\title{
LA DOCTRINA DEL ENTENDIMIENTO EN AVICENA
}

\author{
Miguel Cruz Hernándes \\ Universidad Autónoma de Madrid
}

\section{RESUMEN}

La doctrina del entendimiento agente de Avicena es una «lectura» islámica de la tradición griega del pensamiento de Aristóteles sobre el tema, con el precedente de la interpretación de al-Fărābr y las conocidas influencias sobre Averroes, Maimónides y la escolástica latina. Por su importancia se traducen los textos esenciales de Avicena.

Palabras clave: Aristotelismo islámico, entendimiento agente separado, Aristóteles, Avicena, escolástica medieval.

\begin{abstract}
Avicenna's doctrine about the active intellect is a Islamic interpretation of aristotelical tradition. Because of significance on medieval scholasticism, on translate the main texts of Avicenna.
\end{abstract}

Key words: Islamic aristotelianism, separate active intellect, Aristotle, Avicenna, medieval scholasticism.

\section{LOS TEXTOS DE ARISTÓTELES}

La doctrina del entendimiento de Avicena ha ejercido una gran influencia en el pensamiento medieval árabe, judío y cristiano. El texto del Siffă' sobre el tema fue traducido al latín hacia el 1150 por Ibn Dāwūd con el título de Liber sextus De naturalibus y desde entonces, acaso empezando con Domingo Gundisalvo, su eco aparece en la totalidad de los textos medievales latinos.

Como es bien sabido, la interpretación aviceniana es una peculiar lectura «árabe» del texto aristotélico sobre el tema, y escribo «árabe» porque ya en al-Kindī y al-Fārāb̄̄ hay antecedentes evidentes de la doctrina aviceniana. En cambio, no existe apoyo suficiente en el texto de Aristóteles que conviene reproducir ahora, y lo hago según los textos traducidos que publiqué en 1988.

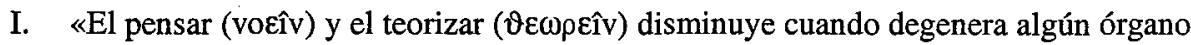
interno, pero el entendimiento (voûs) mismo es impasible» (De anima, 408b, 18-29).

II. «A veces a los hombres se les oscurece el entendimiento por la pasión, la enfermedad o el sueño (Ibidem, 429a, 7-8).

III. «Respecto al entendimiento y a la facultad especulativa nada está aún claro». (Ibidem, $413 b, 24-25)$.

IV. «El entendimiento y la percepción sensible son análogos en cuanto que cada uno de ellos guarda idéntica relación inmediata con su objeto respectivo. Como la vista en el ojo, así es el entendimiento en la $\psi v \chi \chi \eta ́$ ». (Tópicos, 108, 10-11, texto más claro y paralelo del De anima, 429a, 17-18). 
V. «El entendimiento [...] no posee actualidad hasta que piensa. Así, pues, no es lógico

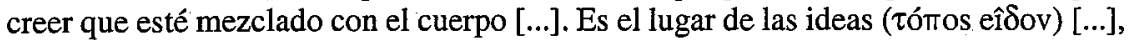
pero tan solo potencialmente [...]. Cuando el entendimiento piensa en lo más alto que puede comprenderse, no por ello es menos capaz de pensar en cosas fútiles [...]. El entendimiento es capaz de pensarse a sí mismo [...]. Y hablando genéricamente, al igual que los objetos son separables de la materia, así también son separables las facultades del entendimiento» (De anima, 429a, 21 a 429b, 22).

VI. «Puesto que en todo tipo de cosas, al igual que en toda la naturaleza, existe algo que es materia (es decir: algo que potencialmente es todas las cosas), y algo diferente que es causa y principio creador con el que se hacen todas las cosas [realmente existentes], relacionados uno y otro del modo como una arte ( $\tau \dot{\chi} \chi \vee \eta)$ y su materia, también es necesario que aquellos elementos se den en la psique ( $\psi$ u $\left.\chi \eta^{\prime}\right)$. El entendimiento (voūs) en sentido potencial (m $\alpha \vartheta \eta \tau i \kappa o ́ \zeta)$ es tal porque viene a ser todas las cosas [como materia]. Pero el entendimiento posee [también] otro aspecto [en tanto causa] por el cual hace todas las cosas [entendibles], éste es una especie de estado positivo como el de la luz. Pues la luz, de algún modo, hace [visibles] actuales a los colores que sólo lo

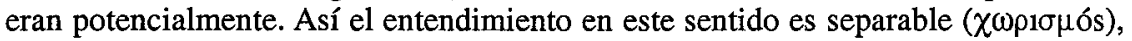

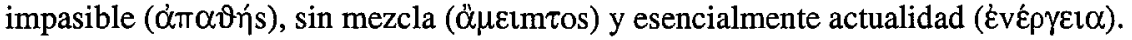

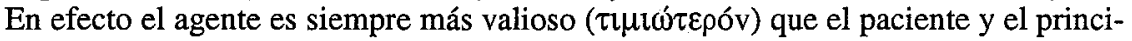
pio $(\alpha \rho \chi \eta ́)$ que la materia $(\dot{v} \lambda \eta \dot{)}$. El conocimiento actual es idéntico a su objeto; en el individuo [concreto] el conocimiento potencial es temporalmente anterior al conocimiento en acto, pero considerado genéricamente no es anterior al tiempo. El entendimiento no piensa a saltos y una vez separado ( $\chi \omega \rho \varepsilon \tau \vartheta \varepsilon t s)$ es su propia verdad

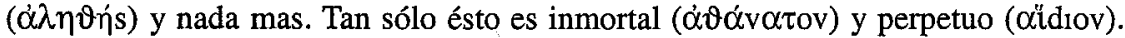
Pero no recordamos [antes de conocer, como creía Platón] porque el entendimiento en este sentido no puede ser actualizado, ya que el entendimiento como potencialidad es perecedero, y sin aquel [el creativo] nada piensa». (Ibidem, 430a, 10-25).

Los anteriores textos, pese a su parquedad y a su estilo poco brillante, ambas cualidades inherentes a la condición de los escritos esotéricos, seguramente nunca pensados para su publicación, posiblemente tienen un sentido original biológico. Como es bien sabido, Aristóteles utiliza su concepción del hilemorfon vivo a la explicación del entender humano. Por tanto el entendimiento es una estructura; que sus comentaristas griegos, musulmanes, judíos y cristianos lo vieran en ocasiones como una cosa, es un problema histórico-filosófico, pero Aristóteles lo que quiso decir es que el entendimiento y el saber inherente a él es verdadero, inmortal y eterno, pese a que los humanos entendientes no lo seamos.

\section{LA LLEGADA AL MUNDO ÁRABE-ISLÁMICO}

La sociocultura árabe-islámica original al extenderse el Islam por un muy amplio espacio geográfico e histórico y tener necesidad de elementos organizadores de los saberes que brotan de su concepción religiosa total del mundo (lecturas coránicas, comentarios, derecho, teología especulativa y espiritualidad), entró en contacto con la sabiduría antigua que a la vez era un saber total, una explicación del cosmos y unas aplicaciones prácticas. Lo más dificil de entender es la atracción que sintió por la filosofía estricta que le llevó a construir la falsafa, un periodo tan brillante como concreto en espacio y tiempo (siglos IX-XI en Oriente y XI-XII en al-Andalus). La idea de los falāsifa (filósofos) islámicos es que la filosofía formaba una continuidad histórica entre los «antiguos» (los griegos) y los «modernos» (los árabes o arabizados). El gran maestro fué Aristóteles, repensarlo es hacer filosofía. Pero lo recibido lo es siempre con la forma del recipiente y éste fue el ámbito cultural del neoplatonismo sirio y alejandrino. $\mathrm{O}$ sea: Aristóteles va acompañado de los continuadores de la filosofía helénica más o menos comentaristas $\mathrm{u}$ originales. 
En el caso que nos ocupa, Aristóteles no llega solo, sino con Temistio y Alejandro de Afrodisia entre otros, incluidas las aporías sobre el De anima de Teofrasto y las ideas de Aristoclés, maestro de Alejandro de Afrodisia. Así los textos del De anima antes citados se relacionan con los de la Metafísica, (lambda 7, 1072b, 14-2.1; 9, 1074, 28-35) y Etica nicomaquea (X, 17, $1177 \mathrm{~b}, 26-34)$. Alejandro de Afrodisia al agregar el entendimiento habitual, y al conferir carácter extrínseco al entendimiento agente, condiciona el problema. Asi, desde al-Kindt (180/796-295/873, aproximadamente) el entendimiento agente es una realidad formal única. Al-Fārābı (muerto en raŷab del 339/ diciembre del 950) presenta la organización del entendimiento de acuerdo con las pautas que luego desarrollaría y universalizaría Avicena, en las que no entro, pues se desarrollarán en otro trabajo incluido en este volumen.

\section{EL ALMA SEGÚN AVICENA}

Por descontado es evidente la preocupación de Avicena por el hombre, su modo de ser y su peculiaridad intelectual, tanto las pautas aritotélicas y la tradición de la falsafa como la propia concepción islámica así lo exigían. En el conjunto hilemórfico humano el determinante es el alma, principio animador del ser vivo, perfección del cuerpo humano al que actualiza.

«El alma racional, que es un cierto sujeto para las formas inteligibles, no está impresa en un cuerpo por el cual subsista, sino únicamente está en posesión del cuerpo como un instrumento, ya que el cambio de estado por la muerte del cuerpo, que cesa entonces de ser un instrumento para ella, no influye de modo alguno en su sustancia sino que lo sobrevive; porque el principio de su ser le es dado por medio de sustancias imperecederas» ${ }^{1}$.

Las más altas de las funciones del alma son las racionales operadas por el entendimiento. A su estudio ha dedicado Avicena un esfuerzo profundo y extendido desde sus primeras obras hasta las últimas, como he indicado en uno de mis últimos trabajos. La amplitud de su consideración puede resumirse en el esquema tomado de mi resumen de su pensamiento en la $\mathrm{His}$ toria del pensamiento en el mundo islámico ( $3^{\mathrm{a}}$ ed., Madrid, 2000, vol. I, p. 254).

\section{EL ENTENDIMIENTO}

Como es sabido Avicena, advierte que el término 'aql es un nombre equívoco (mustarik). Sus diversos sentidos pueden agruparse en dos grupos: común o vulgar y filosófico. En sentido común pueden especificarse tres modos de significación: lucidez mental, conocimientos universales comunes y disposición mental. En el primer caso, lo utilizamos al decir «fulano es muy inteligente» porque lo encontramos perspicaz. En el segundo caso, nos referimos a ciertos conocimientos universales comunes que se han ido adquiriendo por la experiencia y que hace a alguien entendido en este $u$ otro quehacer. En el tercer y último sentido lo utilizamos como referencia a cierta disposición natural que el hombre común llama inteligencia.

Los significados filosóficos que aparecen en casi todas las obras de Avicena que tratan directa o indirectamente del tema aparecen muy bien resumidos en la definición tercera de la Risălat al-Hudūd. Resumiendo los diferentes textos podemos enumerarlos del modo siguiente:

1 Kităb al-Iŝārăt wa-l-tanbihat, ed. Forget, Leiden, 1892, p.176. Utilizo por lo general, los textos y ediciones que utilicé en 1946 para mi tesis doctoral, publicada en parte en La Metafisica de Avicena, Universidad de Granada, 1949. 
1. El entendimiento distinto de la ciencia que indica los conceptos (tasawwurāt) y las verdades ( $\operatorname{tas} \bar{d} q \bar{a} t$ ) presentes en nuestro espíritu (fitra), que fue expuesto por Aristóteles en los $\mathrm{Se}$ gundos Analíticos.

2. El entendimiento especulativo ('aq al-nazañ) o facultad de la psique que puede recibir las esencias formales de los entes universales en tanto que tales

3. El entendimiento práctico ('aql al-'amath) o facultad afectiva (quwwat al-ŝawqiyya) que tiende hacia los entes concretos que ha aprehendido en relación con un fin determinado.

4. El entendimiento potencial o material ('aql al-hayülānt), llamado material porque puede ser todas las cosas o facultad anímica que es capaz de recibir las esencias de las cosas abstraidas de sus materias concretas.

5. El entendimiento hábito ('aql bi-l-malika) al que se refiere Aristóteles en el libro segundo de los Segundos Analíticos, siendo un grado potencial del entendimiento especulativo y que está perfeccionado de tal modo que puede ser considerado como una fuerza cercana al acto.

6. El entendimiento en acto ('aql $b i-l-f c^{c} l$ ) o perfección anímica que permite la intelección y asimilación de las formas inteligibles.

7. El entendimiento adquirido ('aql al-mustafäd) que se comporta como una esencia abstraida de toda materia, adquirida del mundo exterior y grabada en el alma. Presenta así el grado más elevado de preparación intelectual del espíritu y por eso puede llamarse entendimiento santo.

8. El entendimiento agente.

Según Avicena, de los entendimientos dos, tres, cuatro, seis y ocho ha tratado Aristóteles directa o indirectamente en el libro De anima.

La idea raiz de la concepción aviceniana parece ser una distinción del entendimiento como potencia y como inteligencia. En el primer sentido es algo pasivo que se actualiza mediante la recepción de los inteligibles; en el segundo, es la operación y el estado que conducen al conocimiento de la verdad.

«El espíritu humano - se escribe en al-Quwwat al-insāniyya - es el realizado cuando concibe la idea intencional ( $\left.m a^{c} a n i\right)$ mediante la definición y la realidad, limpia a esta idea de todos los caracteres extraños que fluyen de su esencia y la toma por lo que contiene de común a varios. Esto es realizado por la facultad llamada entendimiento especulativo. El espíritu es parecido a un espejo; la facultad es como el pulimentado del espejo; y los inteligibles se imprimen en él procedentès del flujo divino, como las siluetas en el espejo pulimentado [...] siempre que la concupiscencia, la cólera o la sensación no empañen el espejo» ${ }^{2}$.

El entendimiento especulativo tiene como finalidad el alcanzar la certeza sobre la índole específica de los seres cuya existencia es extrínseca a la acción humana, mientras el práctico tiene por fin conducir a una acción adecuada y su finalidad última es el bien. Al alcanzar el ser, el entendimiento especulativo es el más alto y noble del hombre. Pero toda acción especulativa del entendimiento se produce estando en acto para lo que necesita de la operación del entendimiento agente.

\section{EL ENTENDIMIENTO AGENTE}

Avicena enfoca el problema del entendimiento agente desde su doble modalidad de tal entendimiento o considerando a éste como entendimiento separado o dator formarum.. Como tal

2 al-Quwwat al-insäniyya, ed. en la col. Tis rasa $\bar{a}^{c} i l$, El Cairo, 1326/1908, pp. 63-64. 
es una sustancia capaz de pasar de potencia a acto al entendimiento humano que es capaz por sí mismo de abstraer los inteligibles siempre que tenga el concurso de dicho entendimiento agente, pues el entendimiento está sometido al principio general metafísico de que nada puede pasar de potencia a acto sin la acción de algo que esté en acto. Así, pues, el entendimiento humano necesita de algo «que siendo en esencia un entendimiento, sea causa de que todo lo que sea entendimiento potencial pase a entendimiento en acto, y que sea suficiente para causar este paso de la potencia al acto en los entendimientos. Por relación con los entendimientos que están en potencia y por su intermedio pasan a acto, se llaman a tal entendimiento agente. El entendimiento agente es a nuestras almas, que son entendimientos en potencia, y a los inteligibles, que son inteligibles en potencia, lo que el sol es para nuestros ojos, que son videntes en potencia, y para los colores, que son visibles en potencia. Su acción hace pasar a unos y otros de potencia a acto [...] De este modo, de este entendimiento agente desborda una potencia que se extiende sobre las cosas imaginadas, que son inteligibles en acto, y para hacer del entendimiento en potencia un entendimiento en acto. Así, lo mismo que el sol es visible por sí y es, además, causa [de la visión], porque convierte lo que era visible en potencia, visible en acto, igualmente esta esencia es por sí misma inteligible y causa al mismo tiempo [de la intelección], porque convierte en inteligibles en acto los demás inteligibles que estaban en potencia» ${ }^{3}$.

En el Sifà 'ya estaba perfectamente desarrollada esta antigua concepción aviceniana: «Los pensamientos y las consideraciones son movimientos que preparan al alma para recibir el flujo, lo mismo que el término medio [de un silogismo] prepara la conclusión, aunque la primera [operación] se hace de un modo y la segunda de otro [...] Cuando el alma racional esta en relación con estas formas por medio de la irradiación del entendimiento agente, algo nace que es en cierto modo del mismo género que aquellas y que en cierto modo no es del mismo género. Así, cuando la luz se refleja sobre objetos coloreados produce en el ojo una impresión que procede de ellos y que no es completamente semejante a él. Del mismo modo, las imágenes inteligibles en potencia pasan a inteligibles en acto, no en sí mismas, sino lo que ha sido recogido sobre ellas. Como la impresión obtenida por medio de la luz y [sacada] de las formas sensibles no es estas mismas formas, sino algo que se relaciona con ellas, que nace por intermedio de la luz en el que recibe el objeto que está frente a él» ${ }^{4}$.

La dificultad de esta concepción no se le escapa a Avicena que ha recurrido a la metáfora y a la descripción simbólica para intentar aclararla. Así, en el lt $b \bar{a} t$ al-Nubuwāt ha realizado un comentario a la aleya de la luz (Alcorán, 24,35) que dice:

«Dios es la luz de los cielos y la tierra. Su luz es comparable a [la de] un nicho en el que hay un candil encendido. El candil está en un fanal de vidrio cual estrella fulgurante. Se enciende [con aceite] de un árbol bendito, un aceituno que no es del oriente ni el occidente y cuyo aceite alumbra casi sin que le haya tocado el fuego. Luz de luz, Dios dirige a su luz a quien quiere; Dios propone parábolas a los hombres; Dios conoce todo».

El comentario de Avicena rebosa agudeza y belleza pero encierra un «sin que le haya tocado el fuego» que no resuelve todas las dudas. Dice así:

«El sentido metafórico [de la palabra luz] se entiende en dos sentidos: del bien o de la causa que produce el bien [...] quiero decir que Dios, jensalzado sea!, es un bien en sí y es, además, la causa de todo bien. Asi, el juicio es sobre lo esencial y lo no esencial. La expresión los cielos y la tierra significa el todo; nicho quiere decir el entendimiento material y el alma racional, pues el nicho está en un muro para disponer mejor el alumbrado, ya que todo lo que está junto a los muros refleja mejor y da más luz. Así, lo mismo 
que el entendimiento se asemaja a la luz, de igual modo lo que recibe el entendimiento se asemeja al cuerpo que recibe la luz, es decir, a lo transparente. El mejor transparente es el aire y la mejor atmósfera es el nicho. El nicho representa el entendimiento material que tiene, respecto del entendimiento adquirido, la misma relación que el nicho con la luz. El candil representa el entendimiento adquirido en acto, ya que la luz es una perfección para lo transparente [...] y hace pasar [al entendimiento material] de potencia a acto. Así, el entendimiento adquirido mantiene respecto del entendimiento material la misma relación que el pábilo respecto del nicho [...]».

Dice después: «Como una estrella fulgurante, porque [el pábilo] está hecho de vidrio puro y transparente, no de vidrio coloreado, pues nada de lo coloreado puede ser considerado transparente. Se enciende [con aceite] de un árabol bendito, representa la facultad reflexiva, que es el sujeto y la materia de los actos intelectivos, del mismo modo que el aceite es el sujeto y la materia del pábilo. Ni del oriente ni del occidente: el oriente designa clásicamente el lugar por donde aparece la luz y el occidente aquel por el que se pierde. Metafóricamente el oriente indica el lugar donde habita la luz y el occidente donde desaparece [...]; su frase: ni del oriente ni del occidente es una imagen de lo que aqui decimos: la facultad reflexiva, en sentido absoluto, no es una de las facultades puramente racionales en las cuales naciera la luz en sentido absoluto [...] Tampoco es, ni mucho menos, una de las facultades bestiales o animales en las que se pierde su luz. [...]. Cuyo aceite alumbra sin que le haya tocado el fuego, es una alabanza de la facultad reflexiva, pues el decir sin que le haya tocado el fuego se están expresando los dos contactos: la unión y el flujo. Llama fuego en sentido metafórico a lo que da luz [...] esto es, al entendimiento universal. Este entendimiento no es como suponia Alejandro de Afrodisia (la opinión se remonta a Aristóteles) el Dios verdadero y primero. Porque este entendimiento primero es uno, en un sentido y múltiple [en otro] en tanto está constituido por formas universales; y no es uno por esencia, sino uno por accidente, ya que posee la unidad que le es conferida por quien la posee por sí mismo que es el Dios único» 5 .

Como los Is $\hat{a} \bar{r} \bar{a} t$ fueron cuando menos rehechos al final de la vida de Avicena, el texto sobre el entendimiento agente aclara aproximadamente la función de dicho entendimiento:

«La sustancia que recibe la impresión causada por los inteligibles [...] no es corporal ni divisible; por tanto nada hay en ellos que sea semejante a un libre administrador, ni parecido a un tesoro, tampoco conviene que ella misma [per se] sea como un algo que administre libremente, mientras que alguna parte del cuerpo o alguna de sus facultades fuese como un tesoro, ya que los inteligibles no se imprimen en un cuerpo. Solo queda, pues, que exista algo extrínseco a nuestra sustancia en el cual estén las formas inteligibles, lo que sería [por tanto] una sustancia intelectual en acto cuando se produjese entre ellos y nuestras almas una cierta unión por la cual se imprimiesen en aquella las formas inteligibles [...] Después, cuando el alma se aparta de él [y se vuelve] hacia lo que está avecindado en el mundo corporal, o hacia otra forma, enseguida se borra la semejanza que existía, como si el espejo por medio del cual el alma miraba hacia el lado de la santidad se hubiese vuelto [para orientarse] hacia el lado de los sentidos o hacia otra cosa santa. $\mathrm{Y}$ aquello no pertenecerá de nuevo al alma hasta que haya adquirido el hábito de la unión [con el entendimiento agente]. Esta unión tiene por causa una facultad remota, el entendimiento material; una facultad adquisitiva, el entendimiento hábito; y una facultad perfectamente preparada que tiene por misión orientar al alma, cuando lo desea, hacia el lado de la iluminación por medio de una disposición sólidamente establecida y que se llama entendimiento en acto» ${ }^{6}$. 
Las dificultades de esta concepción fueron vistas primero, por Averroes, en un sentido muy peculiar, pues le conduce a la teoría de la unidad del entendimiento material de todos los hombres, y en otro sentido por la escolástica latina desde finales del siglo XII hasta la aparición del averroísmo latino, pero ello escapa de los límites de esta mi contribución al tema que nos ocupa. $^{7}$

Miguel Cruz Hernández

Francisco Gervás, 9 28020 Madrid

7 Desde principios de 1946 hasta ahora he tenido que resumir mi exposición de este tema al menos en ocho ocasiones, contando con la presente. Salvo pequeñas matizaciones en las traducciones creo que la versión inicial, publicada en 1949, conserva su valor, acaso porque cuando trabajé en 1946, la escasez de bibliografía asequible me permitió una mayor libertad y un más duro trabajo. Por razones obvias no debo entrar en una crítica histórico-filosófica ni doctrinal del tema que rompería el esquema del orden de nuestras intervenciones. 